\title{
From Doing to Thinking: Developing the Entrepreneurial Mindset through Scaffold Assignments and Self-Regulated Learning Reflection
}

https://doi.org/10.1515/edu-2019-0007

received January 28, 2019; accepted July 12, 2019.

\begin{abstract}
Engineer, innovators, and designers play a critical role in the economy by addressing pressing problems and creating solutions that are new and innovative. It is a role that involves technical skills but also requires curiosity, an ability to connect pieces of knowledge to discover solutions, and a focus on value creation - which are all characteristic of the entrepreneurial mindset. There are many different design-focused frameworks that can be used to enhance the entrepreneurial mindset; this study focuses on four of them: systems thinking, design thinking, the value proposition canvas, and the business model canvas. The purpose of this paper is to highlight a new approach to developing the entrepreneurial mindset that goes beyond the proverbial "checking boxes" to providing an approach for demonstrating the integration of doing (artifact development) and thinking (reflection). This innovative and experimental approach offers two unique attributes. First, it is a scaffold in that instruction of each of the four modules builds on the other, further enhancing and grounding the learning experience. Second, students are required to continuously reflect on the process. This encourages students to think about learning in a holistic manner, allowing the ability to connect classroom learning with specific current and future utility. The findings suggest that students were able to recognize why the design-focused frameworks and learning activities were important outside of the classroom, particularly in relation to workforce preparation and securing future employment.
\end{abstract}

Keywords: self-regulated learning; reflection; food access; higher education; undergraduate.

*Corresponding author: Lisa Bosman, Purdue University, West Lafayette, United States, E-mail: lbosman@purdue.edu

\section{Introduction}

\subsection{Overview of the Entrepreneurial Mindset}

Engineers, innovators, and designers play a critical role in the economy by addressing pressing problems and creating solutions that are new and innovative. This role is not played in isolation, but rather requires collaboration and leadership. It is a role that involves technical skills but also requires curiosity, an ability to connect pieces of knowledge to discover solutions, and a focus on value creation - which areall characteristic of the entrepreneurial mindset. By definition, the entrepreneurial mindset is "the inclination to discover, evaluate and exploit opportunities (Bosman \& Fernhaber, 2018).” Developing an entrepreneurial mindset is not only important for startups but is also important for everyday people working in well-established organizations, government, and education, to name a few. An entrepreneurial mindset can be characterized by five key attributes: passionately seeking new opportunities, pursuing opportunities with discipline, pursuing only the very best opportunities and avoid risky opportunities, focusing on adaptive execution, and being exceptional at engaging energy and resources within their network (McGrath \& MacMillan, 2000). Finally, the entrepreneurial mindset cannot be obtained overnight; instead, it takes practice in order to become a habit. And because a mindset develops over time and requires practice, the role of educators is to discover opportunities throughout a student's coursework to infuse this approach into learning (Beiler, 2015).

\subsection{Design-Focused Frameworks for Education}

Design thinking, a process used to develop the entrepreneurial mindset, has received increased accolades as a respected teaching technique in higher 
education (Dunne \& Martin, 2006; Dym, Agogino, Eris, Frey, \& Leifer, 2005; Koh, Chai, Wong, \& Hong, 2015; Scheer, Noweski, \& Meinel, 2012a). In addition to design thinking (Brown, 2009), the Stanford d.school has gone through great efforts to popularize teaching methods and lesson plans associated with systems thinking (Seddon \& Caulkin, 2007), the value proposition canvas (Osterwalder, Pigneur, Bernarda, \& Smith, 2014), and the business model canvas (Osterwalder \& Pigneur, 2010), all of which can be used to enhance the entrepreneurial mindset through design-focused learning experiences. Research has uncovered numerous benefits of participating in these design-focused learning experiences including, but not limited to, increased skill development associated with empathy (Brown \& Wyatt, 2010), creative thinking (Owen, 2007), experimentation and prototyping (Razzouk \& Shute, 2012), problem-solving (Beckman \& Barry, 2007), and brainstorming (Seidel \& Fixson, 2013), to name a few. The use of these design-focused frameworks (e.g., design thinking, systems thinking, value proposition canvas, and business model canvas) in an educational setting encourages students to identify, scope and solve problems (Wheadon \& Duval-Couetil, 2016) and assists in the development of an entrepreneurial mindset (Bosman \& Fernhaber, 2018). In summary, the literature offers many benefits of curriculum development and integration of design-focused frameworks into the higher education classroom. Yet, limited resources exist around best instructional practices and assessment for a better understanding of potential mindset changes and habit development as students engage in design-focused learning activities over time (or throughout a semester). In addition, there is a need to better understand a student's ability to connect the classroom learning to authentic and real-world experiences (Bosman \& Fernhaber, 2019).

\subsection{Purpose of this Study}

The purpose of this paper is to highlight one approach to developing and assessing the entrepreneurial mindset within a semester-long course for students working on a bachelor's degree in Transdisciplinary Studies in Technology. Students were introduced to four designfocused frameworks (e.g, systems thinking, design thinking, value proposition canvas and business model canvas), each offered as a stand-alone, yet scaffolded, module requiring the creation of an artifact and submission of a reflection geared towards self-regulated learning. The benefit of scaffold learning is that it progressively and iteratively leads students towards greater learning and depth of understanding through continued practice and connection of materials from one step to the next (Crismond, 2001). It is scaffolded in that instruction of each of the four modules builds on the other, further enhancing and grounding the learning experience. The use of a scaffold, funnel down approach, starting with systems thinking and design thinking and ending with the value proposition canvas and business model canvas, is intentionally applied to guide students from an (a) big picture, endless problems, systems-level perspective down to (b) problem-solution fit exploration to (c) problem-solution fit identification to (d) commercializing a solution. The benefit of self-regulated learning reflection is that it permits students to think about learning in a holistic manner, allowing the ability to connect classroom learning with specific current and future utility (Autrey, Sieber, Siddique, \& Mistree, 2018). Additionally, this approach to innovation helps students narrow their scope and the continuous momentum towards transdisciplinary doing/thinking emboldens students to think outside the box. The guiding research questions are as follows:

1. How can integrating self-regulated reflections into design-focused projects help students articulate their understanding of why the approach is important for the workforce and future employment, and help students consider how they might respond to similar experiences in future applications?

2. How can scaffold design-focused assignments influence student perceptions and assist with habit development as progression occurs over time?

\section{Background}

\subsection{Design-Focused Frameworks to Cultivate the Entrepreneurial Mindset}

The literature offers insight into several designfocused frameworks which can be used to enhance the entrepreneurial mindset (Guerra et al., 2014; Liening, Geiger, Kriedel, \& Wagner, 2016; Patel \& Mehta, 2017). This paper will focus on four frameworks including systems thinking (Seddon \& Caulkin, 2007), design thinking (Brown, 2009), the value proposition canvas (Osterwalder et al., 2014), and the business model canvas (Osterwalder \& Pigneur, 2010).

Systems thinking is an approach to the analysis of complex problems in which an individual can understand a system as a whole by describing the discrete constituents of the system in isolation and analyzing in 
detail the connections and interaction among the discrete constituents (Seddon \& Caulkin, 2007). It has been applied in many educational settings, and the benefits include improvements in holistic thinking and conflict resolution skills among the students. The improvement is maximized when systems thinking skills are integrated throughout the course rather than as an attachment to the curriculum (Hiller Connell, Remington, \& Armstrong, 2012). The students demonstrate abilities to identify the individual parts of a system, their interactions, modelling complex systems from data and using systems thinking approach to solve societal problems (Gilbert, Gross, \& Kreutz, 2018). Also, the students exhibit increased content knowledge and confidence while working on solving complex problems and so courses must be designed with increased scaffolding to develop higher-order thinking skills (McNeal et al., 2014).

Design thinking provides a human-centered and solution-based approach to solving problems (Brown \& Wyatt, 2010). Design thinking has been applied in many educational settings and the benefits include a positive shift in knowledge and understanding of design responsibilities among the students (Behm, Culvenor, \& Dixon, 2014). Other advantages exist in that design thinking improves metacognitive skills and competencies when used as a formalized process (Scheer, Noweski, \& Meinel, 2012b). Design thinking has proven project continuation rate beyond the end of the semester and student dedication to the project beyond the academic expectations of the course thereby progressing towards merits and awards (Ranger \& Mantzavinou, 2018).

The value proposition canvas is a visual document showcasing customer jobs and needs, shown in alignment with a product or service features (Osterwalder et al., 2014). It has been applied in many educational settings and the benefits include enabling students to predict at the initial phases whether a product will be successful or not and the development of communication and negotiation skills among students to progress towards a better design (Kline et al., 2014). The value proposition canvas enables positive shifts in student perceptions on development of entrepreneurially minded skills such as creativity, curiosity, leveraging newer opportunities and risk assessments (Welker, Sample-Lord, \& Yost, 2017). The other advantages include providing an opportunity for the students to understand and experience team work, problem solving and customer awareness (Gerhart, Carpenter, Fletcher, \& Meyer, 2014).

The business model canvas is a strategic business tool composed of nine building blocks that assists organizations to plan their activities and perform analysis of their business scenario (Osterwalder \& Pigneur, 2010). It is used to analyze the organizational performance and calibrate specific blocks. It has been applied in many educational settings and the benefits include developing an in-depth understanding of a business opportunity, assessing multiple options before forming a business plan, introducing students to opportunities and challenges associated with venturing into business as observed through student feedback (Leschke, 2013). With the business model canvas, higher levels of enterprise potential attitudes can be observed, such as leadership, creativity, achievement and intuition when using a business model methodology of entrepreneurship education (García-Rodríguez, Gutiérrez-Taño, \& RuizRosa, 2017). The other advantages include providing an opportunity to have an increased in-depth understanding of a problem, increased awareness of the importance of business models, and increased development of communication and presentation skills by exhibiting their solutions (Hoveskog, Halila, \& Danilovic, 2015).

\subsection{Scaffold Learning}

Scaffold learning promotes the use of assignments that are built progressively to provide knowledge in which the teacher provides just enough support at each step in the scaffold and removes them gradually as the learner improves on the skill sets (Eppes, Milanovic, \& Sweitzer, 2012). Presented here are several examples where scaffold assignments have been incorporated into the higher education classroom. Fisher and Justwan (2018) used a variety of scaffold assignments for teaching research method courses. The courses, offered through two different universities, aimed to provide students exposure to the political sciences, gain statistical literacy and conduct data analysis. Through student feedback and course evaluations the authors have demonstrated that the scaffold assignments have made the course easier to navigate and have increased student satisfaction. Wass, Harland, and Mercer (2011) describe the development of critical thinking skills, among the students enrolled in a Zoology program, through scaffold learning. The paper investigates the educational experiences of students using an open interview framework for three years with reflection writing being an important tool. The authors found clear demonstration of changes in student experiences of critical thinking, evaluative skills and newer perspectives of knowledge from first year to the third year. Hathcock, Dickerson, Eckhoff, and Katsioloudis (2015) conducted a case study involving ninth grade students participating 

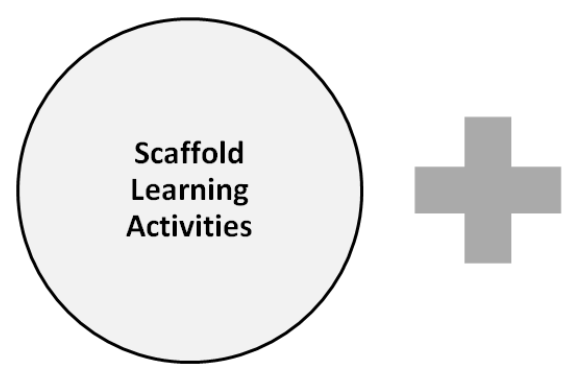
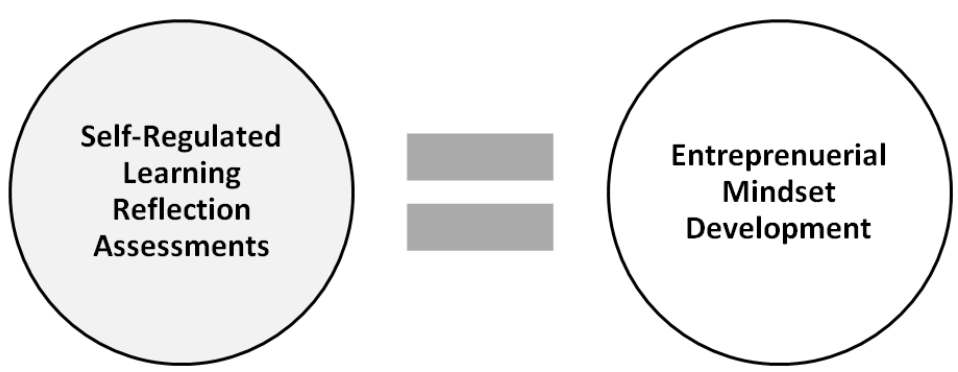

Figure 1. Overview of the Study

in a STEM residential camp to understand the creativity observed in a scaffold design-based activity. The facilitators used the question based scaffolding approach to support the students iterative design of a buoy. Interviews were conducted following the activity. The authors found that inquiry-based scaffold questioning promoted product creativity and design maximization. Eppes et al. (2012) developed an Improved Capstone (ICap) Course using scaffold assignments. Three modules, namely classical, transitional and design of an experiment shape up the assignments. The modules introduce well-defined experiments, design uncertainty, inquiry-based learning and team-based problem solving in a scaffold structure. The modules were assessed on third year students upon entrance into the final year capstone. The authors found that the students gained increased responsibility, design skills, and content knowledge with overall improvement in capstone performance and learning outcomes. Clark and Mahboobin (2018) describe a case study of a junior level bio-signals course that adopted a scaffold approach to the laboratory portion of the class. The students were required to solve an open-ended project using MATLAB programming with frequent guidance and feedback from the instructor. A preliminary investigation carried out showed that the introduction of scaffolding was helpful and improved the professional behaviors of the student. A post-scaffolding assessment was carried out by using a follow-up course conducted by the same instructor with nearly $100 \%$ of the same students who enrolled for the earlier class. Qualitative analysis was conducted on the assessment, which showed that the scaffold approach helped the students skill development related to MATLAB programming, experimentation, modelling and data analysis, and writing.

\subsection{Design-Focused Learning Assessments}

The literature on the topic of design-focused learning assignments and activities is filled with examples of assessment with a particular focus on five key grading and evaluation indicators. These indicators include process, outcome, content knowledge, teamwork, and communication. For process-related design assessments, instructors assess based on whether or not students follow and apply all the steps of the design-focused process (Bailey \& Szabo, 2007). For outcome-related design assessments, instructors assess based on the extent to which the final project demonstrates a "winning solution” (Kudrowitz \& Wallace, 2013). For content knowledge assessments, instructors assess student ability to provide evidence of technical feasibility with respect to connecting projects to theoretical content commonly obtained from science or engineering coursework (Hicks, Culley, Allen, \& Mullineux, 2002). For teamworkfocused assessments, students are assessed based on contribution and leadership skills, commonly evaluated by peer-reports, self-reports, and instructor observations (Andersen, 2001). Finally, communication-based assessments allow instructors to evaluate a project with respect to the potential of the idea, typically based on a final presentation or report (Estell \& Hurtig, 2006). The previously mentioned assessment approaches ensure students are able to master the "doing" but provide little emphasis on the "thinking." Little is known about selfregulated learning and reflection within the context of design-focused projects.

\subsection{Curriculum Development for this Study}

The overall premise of the study, visually depicted in Figure 1, is the combination of scaffold learning activities and self-regulated learning reflection assessments can be 
used to develop the entrepreneurial mindset. This concept is further detailed in the Discussion section.

\section{Methods}

\subsection{Participants}

Participants included undergraduate students enrolled in a bachelor's degree program in transdisciplinary studies in technology. Ten students participated in the study, including five females and five males. All participants were enrolled full-time at the research-intensive university located in the Midwest, U.S.A. Five of the participants were freshman, two were sophomores, and three were junior level students. The study design was approved by the university IRB \#1808020877 as Exempt Category (1). As a result, students were notified that the class assignment would be used for research purposes.

\subsection{Study Design and Data Collection}

First, at the beginning of the semester and at the end of the semester, students completed a pre- and post-survey with the open-ended questions provided here.

1. When faced with a learning opportunity, how do you assess barriers and motivators, and overall ability to complete the task within a timely manner? [2-3 sentences]

2. How do you decide what you need to learn and the overall approach to learning? [2-3 sentences]

3. Upon completing a learning experience, how do you know if it was worth learning? [2-3 sentences]

4. If you were to participate in a similar learning experience again, would you approach learning it in a different way? Explain. [2-3 sentences]

Second, at the beginning of the semester, students were given a design challenge: "How might University students, faculty, staff, and visitors better access healthy and affordable food?". The students participated in a series of four scaffold modules throughout the semester: (1) systems thinking, (2) design thinking, (3) value proposition canvas, and (4) business model canvas. This funnel approach to design and innovation was intentionally applied to guide students from an (a) big picture, endless problems, systems-level perspective to (b) problem-solution fit exploration to (c) problem-solution fit identification to (d) commercializing a solution.
Each module included a human-based design activity incorporating a new framework (shown in Figure 2) and information obtained from interviewing other potential customers. In addition, each module required students to submit a five-page reflection responding to a standard set of self-regulated learning prompts. An overview of the semester-long scaffold curriculum is provided in Appendix A. An example set of reflection prompts are provided in Appendix B.

\subsection{Data Analysis}

This study followed a qualitative approach using thematic analysis. According to Braun and Clarke (2006), a thematic analysis is a foundational qualitative method for discovering patterns within the data. It should be conducted using a step-by-step process. The researchers first became thoroughly familiar with the data to generate initial codes. The NVivo 11 qualitative analysis software was used to analyze the pre- and post-survey question responses and submission of the four reflections (including visual summary of the learning experience and key takeaways). Upon the completion of coding, themes were generated. As a final step, the researchers revised the themes and wrote the report. The researchers debated the strengths and weaknesses between strictly conceptualizing themes without quotes and heavily using quotes to provide readers with evidence. It was decided to merge the two philosophies and meet in the middle. Quotes were drawn from the data to allow readers to make their own judgements on credibility, accuracy, and fairness (Corden \& Sainsbury, 2006).

\section{Results}

\subsection{Self-regulated Learning Reflections to Connect Workforce and Future Employment}

Systems thinking is an approach to analysis of complex problems in which an individual can understand a system as a whole by describing the discrete constituents of the system in isolation and analyzing in detail the connections and interaction among the discrete constituents (Seddon \& Caulkin, 2007). Analysis of student reflections provided a number of key words related to systems thinking: Decision making, communicating the value proposition, reflection and goal setting, problem identification, component interaction and complexity, project planning, 

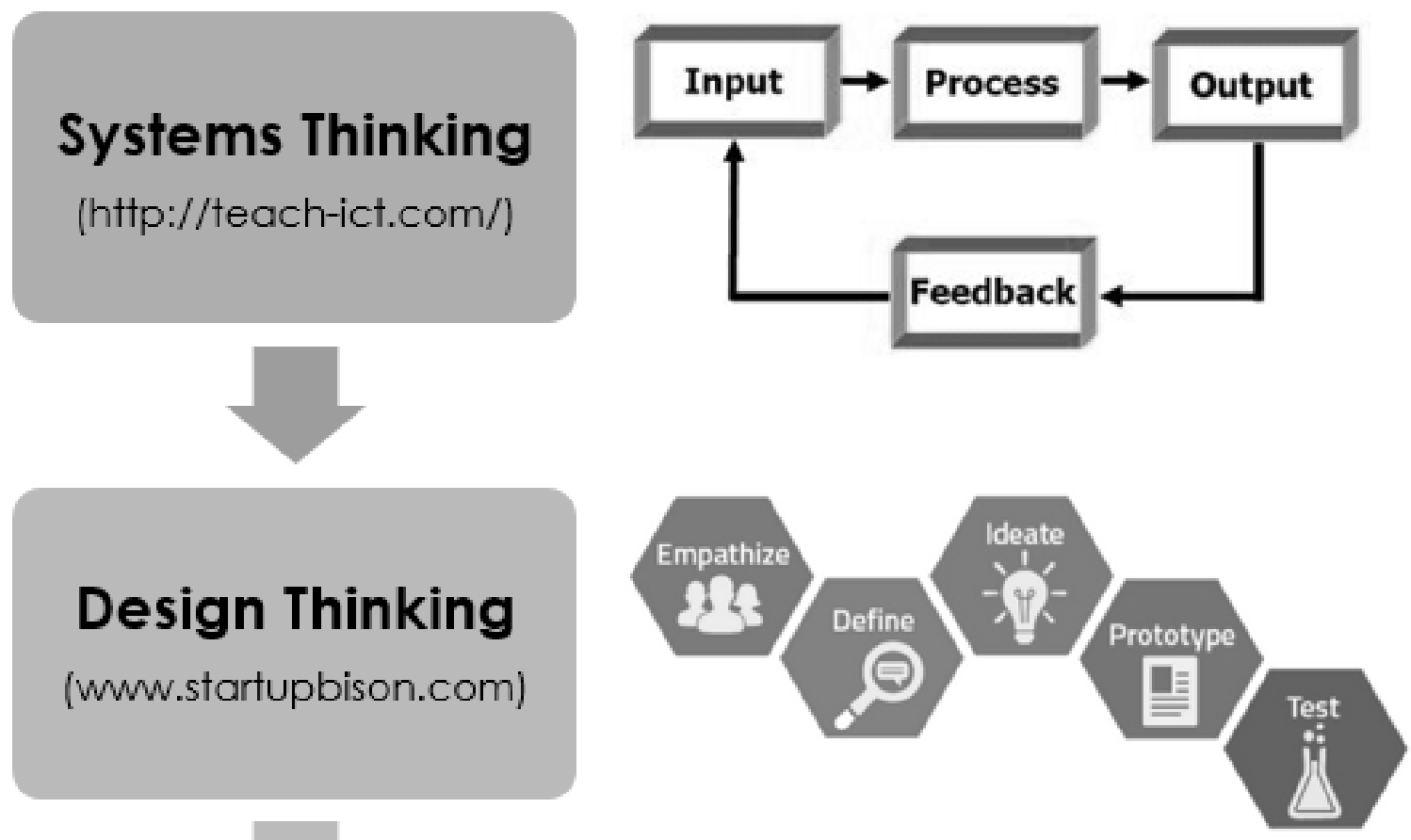

\section{Value Proposition}

(mun.stratagyzer.com)

\section{Business Model}

(wmw.startegyzer.com)
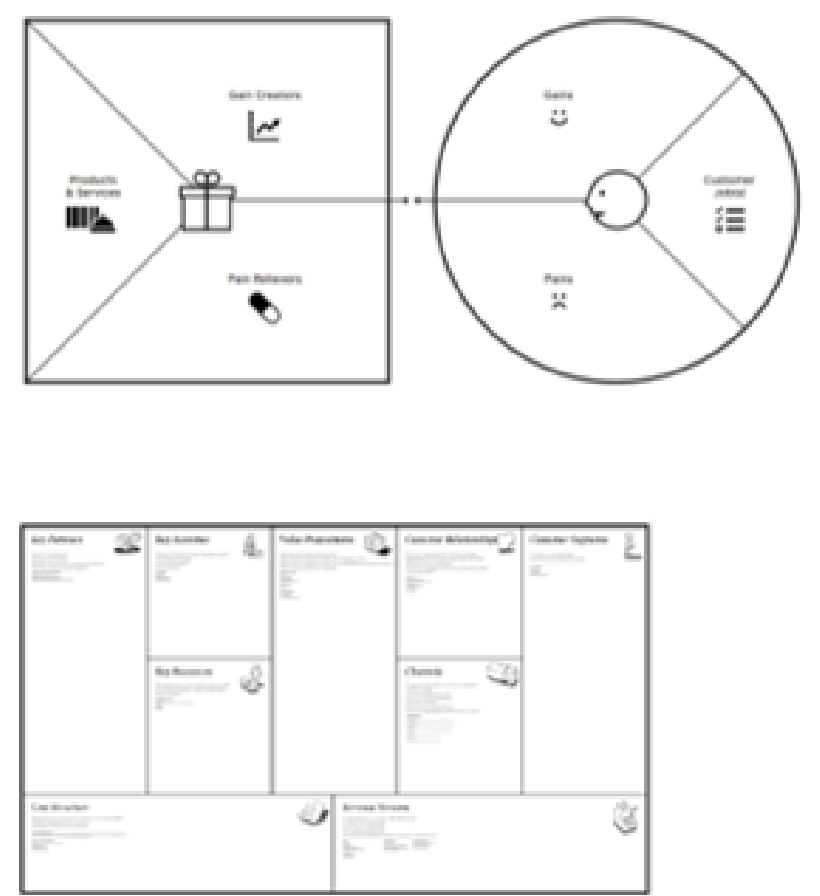

Figure 2: Design-Focused Framework Modules 
scope identification, practical problem solving, reflection and goal setting, and integrated design. In general, students were able to recognize why the systems thinking learning activity was important outside of the classroom particularly in relation to workforce preparation and securing future employment. Student 1 said, "Once I go into the industry I realize it's much more effective to take a little more time to think about the decision rather than just diving into whatever action that I think is better at that exact point in time." Student 2 said, "If I were to find my future in marketing, I would most likely have to use systems thinking to develop a convincing advertising campaign by presenting why people need things, and how these things would help." Student 6 said, "System thinking is also a skill that is largely desired nowadays the ability to understand what needs to be done in what order and how it is to be done is the basis to a large part of any job, and undoubtedly highly sought-after.” Student 7 said, "This way of thinking can be very useful when dealing with big projects that are difficult to grasp at first." Student 10 said, "I can use this perception in system thinking in my future development to consider the impact of what I design or use to design to help the whole system rather than just the current subject."

Design thinking provides a human-centered and solution-based approach to solving problems (Brown \& Wyatt, 2010). Analysis of student reflections provided a number of key words related to design thinking: reasoning skills, active listening and communication, flexible thinking, customer-centric design, effective listening, critical thinking, problem identification, systems thinking, and problem solving. In general, students were able to recognize why the design thinking learning activity was important outside of the classroom particularly in relation to workforce preparation and securing future employment. Student 1 said, "To an employer, someone that is deeply grounded in design thinking is sure to be more rational and less brash when making important deals." Student 3 said, "Design thinking is critical to working in a team because there is room for feedback from people who may have different perspectives than you." Student 4 said, "It is important to society to have the skill of design thinking because that way products are designed with the end user in mind." Student 5 said, "The interview was a good learning experience for me in particular. It not only taught me how to understand someone else's point of view better, but it could also be applied to job interviews in the future." Student 9 said, "From a career perspective, I'm excited about this competency completion because I feel like it's very relevant to my area of interest in terms of being able to take that initial iteration into a final design".
The value proposition canvas is a visual document showcasing customer jobs and needs, shown in alignment with a product or service features (Osterwalder et al., 2014). Analysis of student reflections provided a number of key words related to the value proposition canvas: customercentric design, decision making, problem definition, creative problem solving, flexible thinking, advertising skills, process improvement, questioning skills, information processing, and communicating the value proposition. In general, students were able to recognize why the value proposition canvas learning activity was important outside of the classroom particularly in relation to workforce preparation and securing future employment. Student 2 said, "The purpose of the value proposition canvas is to make sure you are aware of all of your problems before you attempt to create a solution, undoubtedly returning a better, more complete solution." Student 5 said, "Practicing this and looking at issues from various perspectives can make someone a valuable asset to any company or organization. Mastery of this skill can make someone an innovator." Student 7 said, "I feel as though this way of thinking would help with efficient processes in the workforce and also with relationship problems." Student 8 said, "Throughout this process I believe I did improve my ability to be a better problem solver and will continue to ask better, more well-rounded questions to get closer to the solution." Student 10 said, "The skills I was able to practice and perspectives that I tinted my work will matter to an employer and hold merit in the work force by demonstrating that I can work in the Value Proposition Canvas in order to design for a specific archetype of user, as well as communicate and iterate around that user."

The business model canvas is a strategic business tool that comprises nine building blocks that assists organizations to plan their activities and perform analyses of their business scenario (Osterwalder \& Pigneur, 2010). An analysis of student reflections provided a number of key words related to the business model canvas: risk analysis, job skill, value creation, creative intelligence, entrepreneurial mindset, business skills, information processing, effective data presentation, and opportunist thinking. In general, students were able to recognize why the business model canvas learning activity was important outside of the classroom particularly in relation to workforce preparation and securing future employment. Student 1 said, "I think as I move into a career setting, it is becoming more and more important to think about the feasibility of a project. I think having the skillset of being able to create a business model canvas can help you see the financial aspects of a value proposition in 
another light." Student 3 said, "If a person wants to start a business, the Business Model Canvas is an essential part of the foundational layers of that person's company. An entrepreneurial mindset along with the usage of the Business Model Canvas ensures that any new product or company will have economic value." Student 5 said, "In the work world, being able to come up with an original idea is an important and rare skill to have. But, what is even harder to find is someone who not only can come up with an idea, but understand what is necessary for that idea to work." Student 6 said, "By sharpening this skill and opening the entrepreneurial door, I think this assignment helped me put a good step in the right direction for understanding what it will take to be an entrepreneur in the real world." Student 9 said, "To an employer I will be able to demonstrate this skillset by being able to create a visual aid or verbally express how these two components are influencing each other."

\subsection{Self-regulated Learning Reflections to Consider Changes towards Future Applications}

An analysis of systems thinking student reflections provided a number of key words related to systems thinking: long term thinking, analytical thinking, flexible thinking, holistic thinking, problem solving, information processing, job skill, and creative thinking. In general, students were able to reflect about how they might do things differently in the future. Student 2 said, "Throughout all of the problems I face, I can attempt to apply systems thinking to see each individual piece as a part of the whole." Student 3 said, "When I read a project or when I am given a task, I will begin to look at what is in front of me through multiple perspectives." Student 4 said, "I will continue to look at problems in a holistic way and look at the big picture while considering the intricacies of the inner workings." Student 6 said, "An effectivelywritten Inputs-Processing-Outputs model can provide either employees or employers with an understanding of an issue, a process to resolve it, and the anticipated outcome of said issue." Student 7 said, "I think this will help with business and personal projects in the future by being able to break them down objectively and what I need to do to achieve those objectives."

An analysis of design thinking student reflections provided a number of key words related to design thinking: convincing skills, self-efficacy, communication skills, customer-centric design, information processing, cognitive thinking, problem solving, information literacy, and personality development. In general, students were able to reflect about how they might do things differently in the future. Student 1 said, "In the future, I think this process is perfect when needing to prove or argue why the conclusion that was achieved is the best possibility." Student 3 said, "Skills such as being interviewed and being able to answer questions in a short, yet effective manner is important for real life situations such as job interviews or interviews for scholarships." Student 4 said, "In a professional setting I will be ready to create an impact on the user by giving them the thing which they need, which they may not even know they need." Student 6 said, "In the future, I believe I would do this project differently by largely focusing on the graphic organizer and basing a lot of my design off of the questions that it provides; the structure it gives is incredibly helpful, and I realize that now after using it." Student 9 said, "I could apply these things in many of my classes that deal with research as this typically provides for an extensive list."

An analysis of the value proposition canvas student reflections provided a number of key words related to the value proposition canvas: value analysis, value creation, opportunist thinking, apply to future coursework, communicating the value proposition, logical reasoning, holistic thinking, and time management. In general, students were able to reflect about how they might do things differently in the future. Student 1 said, "This canvas helps see it in front of you, and to me feels like a weighted average of the factors involved in a proposition. I can extend my knowledge by applying the canvas to other aspects of life." Student 4 said, "One way for me to continue to extend my knowledge of problem solving is to seek out opportunities to solve problems and receive feedback on my work. I can also apply the value proposition canvas to other projects in the future." Student 6 said, "I believe that when it comes to iterating something for the people, if anything, this assignment has effectively taught me it's a safe bet to always ask not one type of person, but all the people." Student 7 said, "I think knowing this type of problem thinking could help with doing school work, and making more time for it. I also know that the more that you do this, the better you get at it." Student 9 said, "This assignment helped me understand this sort of holistic approach a great deal and I feel like moving forward I will have different approaches."

An analysis of the business model canvas student reflections provided a number of key words related to the business model canvas: project management, entrepreneurial mindset, holistic thinking, customercentric design, flexible thinking, critical thinking, integrated design, effective data presentation, information 
literacy, and opportunist thinking. In general, students were able to reflect about how they might do things differently in the future. Student 4 said, "In a professional setting I will be ready to create an impact on the user by giving them the thing which they need, to solve problems they may realize they had or to address a problem that was making a large or small impact." Student 5 said, "To better design a product, keeping in mind all perspectives, will be extremely useful in these classes, and beyond into my career." Student 6 said, "I believe that this experience will change how I tackle entrepreneurial ideas; by introducing me to the business model canvas, I feel more confident in that the idea can help me explain what I'm thinking clearly, and that goes a long way in the business world." Student 8 said, "All of these skills can relate to almost everything in life when it comes to being able to present information in a well-mannered way, provide research on how what you're saying makes sense, and problem solving." Student 9 said, "I could apply these things in many of my classes that deal with research as this typically provides for an extensive list."

\subsection{Benefits of Scaffold Design-Focused Assignments On Student Perceptions Over Time}

An analysis of the pre- and post-survey responses revealed a variety of themes between the pre- and post-statements, in addition to noteworthy differences between the preand post-statements. First, the learning perspective preparticipation was weakness-focused and the learning perspective post-participation was strengths-focused. Before participating in the course, students generally reported to primarily assess their ability to complete tasks from a deficits perspective with a particular focus on identifying and overcoming challenges and weaknesses. However, after completing the semester-long scaffold assignments, students generally reported to primarily assess the ability to complete tasks from a strengths perspective with a particular focus on learning and growing from past experiences.

Pre-survey example responses are as follows. Student 1 said, "I typically first take a look at any obstacles that might stand in my way or prevent me from completing it on time." Student 2 said, "I look at the parts that I don't fully understand and do my best to learn about those different aspects." Student 4 said, "I compare what is required within the task to my strengths and weaknesses. Once I see where my reach falls I attack my weaknesses with respect to accomplish the task and while doing so build on my strengths. I hypothesize that this methodology with eventually eliminate my weaknesses." Student 5 said, "While there are usually barriers with any opportunity, I do my best to overcome these." Student 8 said, "I believe things I do now could be beneficial to my future so I will try to get by these barriers to be able to learn."

Post-survey example responses are as follows. Student 1 said, "I tend to look at the learning opportunity and asses what I would be best at first. That being said, I play to my strengths when I can." Student 3 said, "I assess by looking firstly at the things that I am capable of which are applicable to the situation at hand." Student 4 said, "[I assess barriers and motivators based on] my experience on prior activities." Student 6 said, "When faced with a learning opportunity, I assess barriers and motivators based on my past knowledge."

Second, prior to participation students viewed all learning as valuable and after participation students insisted that the value of the learning was dependent upon a variety of factors. Before participating in the designfocused educational experience, students generally reported a whimsical and optimistic perspective that all learning was "worth it". However, after completing the semester-long learning experience, students generally reported a more realistic approach to learning valuation which aligns to practical and future applications.

Pre-survey example responses are as follows. Student 1 said, "Any knowledge gained has the potential to be "worth learning". Student 2 said, "Anything is worth learning." Student 3 said, "It's always worth learning. Always." Student 4 said, "I believe in being well rounded so all new information can be useful." Student 5 said, "Everything is worth learning." Student 7 said, "In my opinion, almost everything is worth learning, for good or bad." Student 9 said, "In my opinion, learning is always worth it." Student 10 said, "Every piece of information is meaningful, especially in a classroom setting."

Post-survey example responses are as follows. Student 1 said, "This allowed me to look back on what I had learned and relate it to my current life and future." Student 2 said, "All knowledge is important except for the knowledge you will never use again." Student 4 said, "If it's something I can do again, and will do again." Student 6 said, "I also tend to evaluate whether something was worth learning based on the amount of time and effort I put into it compared to the learning or experience I gained from it." Student 7 said, "This allowed me to look back on what I had learned and relate it to my current life and future." Student 8 said, "At the end of a project, I think about what information I now know vs what I knew in the beginning of the project. If there isn't too much new or revealing information at the 
end of the project that would have drastically influenced it in the beginning, then I would probably refer to it as a job instead of a learning experience."

Third, prior to participation students stated that they would not approach learning differently in the future, yet, after participation students were more open to consider alternative ways of approaching learning. Prior to participating in the design-focused learning experience, students generally reported a "no" or "maybe" perspective on approaching future learning in an alternative way. After completing the learning experience, students generally responded positively to approaching future learning experiences in an alternative way.

Pre-survey example responses are as follows. Student 1 said, "A lot of times if it bores me or I pawn [learning] off as not useful, I don't put in a lot of effort, but could find out later it's more important than I might have first imagined." Student 2 said, "I would not overload myself. I try to do too many things at once and sleep is often what suffers. I will focus on learning but can only do so much at once." Student 3 said, "If I was to participate in a learning experience again I would approach it the same way." Student 5 said, "Maybe, I'm pretty confident in my learning style." Student 6 said, "I don’t really know. I might try to look for improvements." Student 7 said, "No, I wouldn’t. I went it with an open mind and learned as much as I could and believe I benefited greatly from it. I believe going into it with an open mind helped increased how much I learned." Student 10 said, "I think I would try to approach everything the same way. I think being consistent is very important, especially when it comes to learning. Whether it is consistent practice or consistent review."

Post-survey example responses are as follows. Student 1 said, "I would improve this learning experience by trying to outright incorporate some of my other experiences. I have done many projects and assignments and can apply them to a broad base of topics and competencies. I would also have completed the reflections closer to the time of their assignment." Student 3 said, "I would approach the learning experience in a similar [manner], but not the exact way." Student 5 said, "Obviously, I think any human would do it in a different way. You can't even call it a learning experience if you do the same learning again, then it would just be called an experience. You have to do approach another way or what's the point of the experience in general." Student 7 said, "My approach would be relative per the assignment, however I would have communicated with the instructors much earlier regarding my preferences and needs on certain things." Student 10 said, "I would approach the experience in a more hands on light."
- Intention 1: The learning activity should provide an experience to discover, evaluate, and/or exploit opportunities. Opportunities that create the most value should be aimed at customer desirability, technology feasibility, and business viability.

- Intention 2: The learning activity should provide an experience to develop professional skills (collaboration and communication).

- Intention 3: The learning activity should provide an experience for continued practice, reflection, and feedback.

-Intention 4: The learning activity should be aligned with and reinforce the learning goals, learning objectives, and learning assessment.

Figure 3: Being Intentional About Integrating the Entrepreneurial Mindset into Curriculum

\section{Discussion}

The results show the alignment of scaffold assignments and self-regulated learning reflections with the four intentions (Figure 3) for developing entrepreneurial minded curriculum, articulated in the text, "Teaching the Entrepreneurial Mindset to Engineers (Bosman \& Fernhaber, 2018)."

Intention 1 requires that the learning be grounded within the implicit context of course content, the entrepreneurial process and the opportunity context. This encourages students to see value in the learning as it connects theoretical course underpinnings to pragmatic, real-world design experiences. This study addresses Intention 1 through the use of a real-world design challenge, "How might University students, faculty, staff, and visitors better access healthy and affordable food?" to engage students in the design process. In addition, the learning guides students through application of four wellknown design-focused frameworks used within industry's new product development process including (1) systems thinking, (2) design thinking, (3) the value proposition canvas, and (4) the business model canvas. Using a scaffold approach with these frameworks encourages students to engage with the entrepreneurial process iteratively going through the discovery-evaluate-exploit phases (Shane \& Venkataraman, 2000). Finally, focusing on the most valuable design (Brown, 2009) inspires students to consider design attributes related to customer desirability, business viability, and technology feasibility.

Intention 2 requires attention to improving the professional skills of collaboration and communication. This requirement ensures technical-minded students obtain opportunities to develop and improve the "soft skills" demanded by industry today (Byers, Seelig, Sheppard, \& Weilerstein, 2013; Goldberg \& Somerville, 2014; Hanson \& Williams, 2008; Sheppard, Macatangay, Colby, \& Sullivan, 2009). This study addresses Intention 2 in that collaboration and teamwork is required to complete the activities associated with each of the four models. For example, during the design thinking module, students were 
required to interview their peers, infer insights, and work together to brainstorm solutions. This study addressed Intention 2 in that written and visual communication were critical in the reflection process, which required students to create a visual summary of the learning activities and key takeaways in addition to submitting a five-page written summary reflecting on the learning activity.

Intention 3 promotes the development of a mindset through the need for continued practice (Brush, Neck, \& Greene, 2015), reflection and feedback to help mold behaviors and routines into habits, and then habits into the mindset. Mindsets evolve over time and are dependent upon individualized experiences and knowledge acquisition (Gupta \& Govindarajan, 2002). Thus, the entrepreneurial mindset can only be cultivated when students have the opportunity to act and think entrepreneurially on a regular basis (Haynie, Shepherd, Mosakowski, \& Earley, 2010). This study addressed Intention 3 through the scaffold nature of the semesterlong project (which promotes practice and feedback) and the use of reflections to drive inquiry and change within the thought process.

Intention 4 ensures that the entrepreneurially-minded curriculum, like any other pedagogical approaches, needs to be carefully planned to ensure the reinforce of learning goals, objectives, activities and assessment. This study addressed Intention 4 through applying the backward course design process (Wiggins \& McTighe, 2005) aligning the broad learning goals (e.g., development of the entrepreneurial mindset) are connected to specific learning objectives (e.g., By the end of the course, students will be able to demonstrate understanding of multiple entrepreneurially-minded frameworks including (1) systems thinking, (2) design thinking, (3) value proposition canvas, and (4) business model canvas.), which are assessed using tool(s) or method(s) to measure student learning (e.g., reflection and visual prototype development), and that they support the learning process through the proposed learning activity (e.g., activities associated with each of the four design-focused framework modules).

\section{Conclusion}

\subsection{Summary of Findings}

In summary, the funnel approach to the design-focused frameworks was intentionally applied to guide students from an (a) big picture, endless problems, systemslevel perspective down to (b) problem-solution fit exploration to (c) problem-solution fit identification to (d) commercializing a solution. This funnel-down innovation approach helps students narrow their scope. Additionally, the continuous push towards transdisciplinary doing and thinking encourages and results in students thinking holistically and outside the box. In general, the findings suggest that students were able to recognize why the design-focused frameworks and learning activity was important outside of the classroom particularly in relation to workforce preparation and securing future employment. In addition, students were able to reflect about how they might do things differently in the future. The artifacts and reflections suggest that this immersive process encourages deeper transdisciplinary thinking within the design and innovation workspace. Although evidence of student learning outcomes was not collected, the authors are optimistic using the design-focused frameworks again in future classroom settings.

\subsection{Recommendations for Future Research}

In general, future research should continue to investigate effective methods for teaching innovation and design in both academic settings and the workplace. In addition, researchers need to be deliberate and intentional about empirically investigating and validating best practices for educational interventions related to design thinking and other design-focused frameworks. With respect to extending the research objectives offered through this paper, future research could focus on student learnings outcomes and student satisfaction, explore the use of different reflection prompts, supplement the qualitative data collection with quantitative survey instruments, and conduct focus groups to gain a richer understanding of the data. Lastly, although the focus of this research initiative was on engineering and technology students, the authors are confident that applying this approach to designfocused frameworks would likely be successful outside of engineering and technology. Thus, at other institutions, future research could focus on applying this approach with natural science, social science, and humanities courses, to name a few other disciplines.

\section{References}

Andersen, A. (2001). Implementation of engineering product design using international student teamwork-to comply with future needs. European Journal of Engineering Education, 26(2), 179186. 
Autrey, J. L., Sieber, J., Siddique, Z., \& Mistree, F. (2018). Leveraging Self-Assessment to Encourage Learning Through Reflection on Doing. International Journal of Engineering Education, 34(2), 708-722.

Bailey, R., \& Szabo, Z. (2007). Assessing engineering design process knowledge. International Journal of Engineering Education, 22(3), 508.

Beckman, S. L., \& Barry, M. (2007). Innovation as a learning process: Embedding design thinking. California management review, 50(1), 25-56.

Behm, M., Culvenor, J., \& Dixon, G. (2014). Development of safe design thinking among engineering students. Safety Science, 63(C), 1-7. doi:10.1016/j.ssci.2013.10.018

Beiler, M. R. O. (2015). Integrating innovation and entrepreneurship principles into the civil engineering curriculum. Journal of Professional Issues in Engineering Education and Practice, 141(3).

Bosman, L., \& Fernhaber, S. (2018). Teaching the entrepreneurial mindset to engineers. Switzerland: Springer International Publishing.

Bosman, L., \& Fernhaber, S. (2019). Applying Authentic Learning through Cultivation of the Entrepreneurial Mindset in the Engineering Classroom. Education Sciences, 9(1), 7.

Braun, V., \& Clarke, V. (2006). Using thematic analysis in psychology. Qualitative research in psychology, 3(2), 77-101.

Brown, T. (2009). Change by design: how design thinking transforms organizations and inspires innovation New York, NY: Harper Collins.

Brown, T., \& Wyatt, J. (2010). Design thinking for social innovation. Development Outreach, 12(1), 29-43.

Brush, C., Neck, H., \& Greene, P. (2015). A practice-based approach to entrepreneurship education. Evolving Entrepreneurial Education: Innovation in the Babson Classroom, 35.

Byers, T., Seelig, T., Sheppard, S., \& Weilerstein, P. (2013). Entrepreneurship: Its Role in Engineering Education. National Academy of Engineering - The Bridge: Linking Engineering and Society.

Clark, R. M., \& Mahboobin, A. (2018). Scaffolding to Support Problem-Solving Performance in a Bioengineering Lab-A Case Study. Education, IEEE Transactions on, 61(2), 109-118.

Corden, A., \& Sainsbury, R. (2006). Using verbatim quotations in reporting qualitative social research: researchers' views: University of York York.

Crismond, D. (2001). Learning and using science ideas when doing investigate-and-redesign tasks: A study of naive, novice, and expert designers doing constrained and scaffolded design work. Journal of Research in Science Teaching: The Official Journal of the National Association for Research in Science Teaching, 38(7), 791-820.

Dunne, D., \& Martin, R. (2006). Design thinking and how it will change management education: An interview and discussion. Academy of Management Learning \& Education, 5(4), 512-523.

Dym, C. L., Agogino, A. M., Eris, O., Frey, D. D., \& Leifer, L. J. (2005). Engineering design thinking, teaching, and learning. Journal of Engineering Education, 94(1), 103-120.

Eppes, T. A., Milanovic, I., \& Sweitzer, H. F. (2012). Strengthening Capstone Skills in STEM Programs. Innovative Higher Education, 37(1), 3-10.

Estell, J. K., \& Hurtig, J. (2006). Using rubrics for the assessment of senior design projects. Paper presented at the Proceedings of the 2006 ASEE Annual Conference \& Exposition: Excellence in Education.

Fisher, S., \& Justwan, F. (2018). Scaffolding Assignments and Activities for Undergraduate Research Methods. Journal of Political Science Education, 14(1), 63-71.

García-Rodríguez, F. J., Gutiérrez-Taño, D., \& Ruiz-Rosa, I. (2017). The Business Model Approach in Entrepreneurship Education: Impact on Undergraduates' Enterprise Potential. Mediterranean Journal of Social Sciences, 8(3), 11-17.

Gerhart, A. L., Carpenter, D. D., Fletcher, R. W., \& Meyer, E. G. (2014). Combining discipline-specific introduction to engineering courses into a single multi-discipline course to foster the entrepreneurial mindset with entrepreneurially minded learning. In.

Gilbert, L. A., Gross, D. S., \& Kreutz, K. J. (2018). Developing undergraduate students' systems thinking skills with an InTeGrate module. Journal of Geoscience Education, 1-16. doi:1 0.1080/10899995.2018.1529469

Goldberg, D. E., \& Somerville, M. (2014). A whole new engineer. Guerra, R. C. C., Smith, K. A., McKenna, A. F., Swan, C., Korte, R., Jordan, S., . . MacNeal, R. (2014). Innovation corps for learning: Evidence-based entrepreneurship to improve STEM education. Paper presented at the 2014 IEEE Frontiers in Education Conference.

Gupta, A. K., \& Govindarajan, V. (2002). Cultivating a global mindset. Academy of Management Perspectives, 16(1), 116-126.

Hanson, J. H., \& Williams, J. M. (2008). Using writing assignments to improve self-assessment and communication skills in an engineering statics course. Journal of Engineering Education, 97(4), 515-529.

Hathcock, S., Dickerson, D., Eckhoff, A., \& Katsioloudis, P. (2015). Scaffolding for Creative Product Possibilities in a Design-Based STEM Activity. Research in science education, 45(5), 727-748. doi:10.1007/s11165-014-9437-7

Haynie, J. M., Shepherd, D., Mosakowski, E., \& Earley, P. C. (2010). A situated metacognitive model of the entrepreneurial mindset. Journal of business venturing, 25(2), 217-229.

Hicks, B. J., Culley, S. J., Allen, R. D., \& Mullineux, G. (2002). A framework for the requirements of capturing, storing and reusing information and knowledge in engineering design. International journal of information management, 22(4), 263280.

Hiller Connell, K. Y., Remington, S. M., \& Armstrong, C. M. (2012). Assessing systems thinking skills in two undergraduate sustainability courses: a comparison of teaching strategies. Journal of Sustainability Education, 3.

Hoveskog, M., Halila, F., \& Danilovic, M. (2015). Early Phases of Business Model Innovation: An Ideation Experience Workshop in the Classroom. Decision Sciences Journal of Innovative Education, 13(2), 177-195. doi:10.1111/dsji.12061

Kline, W. A., Hixson, C. A., Mason, T. W., Brackin, P., Bunch, R. M., Dee, K. C., \& Livesay, G. A. (2014). The Innovation Canvas in entrepreneurship education: Integrating themes of design, value, and market success. The Journal of Engineering Entrepreneurship, 5(1), 80-99.

Koh, J. H. L., Chai, C. S., Wong, B., \& Hong, H.-Y. (2015). Design thinking and education. In Design Thinking for Education (pp. 1-15): Springer. 
Kudrowitz, B. M., \& Wallace, D. (2013). Assessing the quality of ideas from prolific, early-stage product ideation. Journal of Engineering Design, 24(2), 120-139.

Leschke, J. (2013). Business model mapping: Application and experience in an introduction to entrepreneurship course. Journal of Entrepreneurship Education, 16, 77-92.

Liening, A., Geiger, J.-M., Kriedel, R., \& Wagner, W. (2016). Complexity and Entrepreneurship: Modeling the Process of Entrepreneurship Education with the Theory of Synergetics. In E. S. C. Berger \& A. Kuckertz (Eds.), Complexity in Entrepreneurship, Innovation and Technology Research: Applications of Emergent and Neglected Methods (pp. 93-115). Cham: Springer International Publishing.

McGrath, R. G., \& MacMillan, I. C. (2000). The entrepreneurial mindset: Strategies for continuously creating opportunity in an age of uncertainty (Vol. 284): Harvard Business Press.

McNeal, K. S., Libarkin, J. C., Ledley, T. S., Bardar, E., Haddad, N., Ellins, K., \& Dutta, S. (2014). The Role of Research in Online Curriculum Development: The Case of EarthLabs Climate Change and Earth System Modules. Journal of Geoscience Education, 62(4), 560-577. doi:10.5408/13-060.1

Osterwalder, A., \& Pigneur, Y. (2010). Business model generation: a handbook for visionaries, game changers, and challengers: John Wiley \& Sons.

Osterwalder, A., Pigneur, Y., Bernarda, G., \& Smith, A. (2014). Value proposition design: How to create products and services customers want: John Wiley \& Sons.

Owen, C. (2007). Design thinking: Notes on its nature and use. Design Research Quarterly, 2(1), 16-27.

Patel, S., \& Mehta, K. (2017). Systems, Design, and Entrepreneurial Thinking: Comparative Frameworks. Systemic Practice and Action Research, 30(5), 515-533. doi:10.1007/s11213-0169404-5

Ranger, B. J., \& Mantzavinou, A. (2018). Design thinking in development engineering education: A case study on creating prosthetic and assistive technologies for the developing world. Development Engineering, 3, 166-174. doi:10.1016/j. deveng.2018.06.001

Razzouk, R., \& Shute, V. (2012). What is design thinking and why is it important? Review of Educational Research, 82(3), 330-348.

Scheer, A., Noweski, C., \& Meinel, C. (2012a). Transforming constructivist learning into action: Design thinking in education. Design and Technology Education: An International Journal, 17(3).

Scheer, A., Noweski, C., \& Meinel, C. (2012b). Transforming Constructivist Learning into Action: Design Thinking in Education. Design and Technology Education, 17(3), 8-19.

Seddon, J., \& Caulkin, S. (2007). Systems thinking, lean production and action learning. Action Learning: Research and Practice, 4(1), 9-24.

Seidel, V. P., \& Fixson, S. K. (2013). Adopting design thinking in novice multidisciplinary teams: The application and limits of design methods and reflexive practices. Journal of Product Innovation Management, 30, 19-33.

Shane, S., \& Venkataraman, S. (2000). The promise of entrepreneurship as a field of research. Academy of management review, 25(1), 217-226.

Sheppard, S., Macatangay, K., Colby, A., \& Sullivan, W. M. (2009). Educating engineers: Designing for the future of the field. Hoboken, NJ: Jossey-Boss.
Wass, R., Harland, T., \& Mercer, A. (2011). Scaffolding Critical Thinking in the Zone of Proximal Development. Higher Education Research and Development, 30(3), 317-328. doi:10.1 080/07294360.2010.489237

Welker, A. L., Sample-Lord, K. M., \& Yost, J. R. (2017). Weaving entrepreneurially minded learning throughout a civil engineering curriculum. In (Vol. 2017-).

Wheadon, J., \& Duval-Couetil, N. (2016). Elements of entrepreneurially minded learning: KEEN white paper. The Journal of Engineering Entrepreneurship(7(3)), 17-25.

Wiggins, G. P., \& McTighe, J. (2005). Understanding by Design. Alexandria, VA: ASCD Publications. 


\section{APPENDIX A: Semester Lesson Planning Overview}

Note: Please contact the author for additional details on the lesson plans.

Overall Semester-Long Design Challenge: How might University students, faculty, staff, and visitors better access healthy and affordable food?

\section{Module 1: Systems Thinking}

Introduction: Systems Thinking is based on a philosophy that everything is interconnected and that a problem/ opportunity must be examined within the context of a larger configuration. There are many parts of a problem/ opportunity, and all the parts interrelate and create a system. Systems Thinking is a tool that provides an understanding of the interconnectedness of all things.

Directions:

1. Take notes during the lecture on Systems Thinking and review the presentation slides available through the learning management system.

2. Use PowerPoint (or another visualization software) to draw the system from an Inputs-Processing-Outputs perspective.

3. Find at least three articles online which provide motivation for this challenge. Use the articles (URL footnotes at the bottom of the document) as support to justify and identify opportunities for improvement within each area of the system.

4. Place your name at the top of the document and submit as a PDF to Blackboard.

5. Complete the reflection prompts (provided in Appendix B).

\section{Module 2: Design Thinking}

Introduction: Design Thinking is a solution-focused method incorporating different perspectives and is often used by interdisciplinary teams. The iterative approach promotes a focus on innovation through experimentation. In addition, the human-centered nature of the process integrates continuous sharing of knowledge, feedback and collaboration, as exemplified in this Empathy-based assignment.

Directions:

1. Take notes during the lecture on Design Thinking and review the presentation slides available through the learning management system.

2. Use the worksheets and associated notes taken during class to (a) provide an overview of the design thinking process and (b) your key findings using the results of the systems thinking module as a starting point. The information should be limited to one $8.5 \mathrm{x} 11$ document and developed using software.

3. Place your name at the top of the document and submit as a PDF to Blackboard.

4. Complete the reflection prompts (provided in Appendix B).

\section{Module 3: Value Proposition Canvas}

Part 1

Introduction: The Value Proposition describes how value is created for the customer. The Value Proposition Canvas visually shows how value is created for the customer. It ensures the gains and pains of the customer jobs (customer needs) are identified, and solved by a specific product or service that relieves pain or creates gain (demonstrated by design features), while taking into consideration current solutions (competitive quantitative performance), and clearly explaining the value proposition summary (What are key differentiators distinguishing your product or service from current solutions?). A tool for developing the Value Proposition Canvas, as shown below, is provided as an attached template.

Directions:

1. Take notes during the lecture on the Value Proposition Canvas and review the presentation slides available through the learning management system.

2. Fill in the Value Proposition Canvas template based on your findings from the design thinking empathy assignment.

3. Place your name at the top of the document and submit as a PDF to Blackboard. 


\section{Part 2}

Introduction: Good customer interviews are a cheap and fast way to kick off the search and design of your Value Proposition. Here are a few hints for conducting interviews: Adopt a beginner's mindset, Listen more than you talk, Ask "why" to get real motivations, Remember: the goal is to learn not sell, Always open doors at the end (provide a way for them to follow up as needed).

Directions:

1. Identify your archetype. Interview 5 people that fit the archetype. Ask questions to obtain qualitative feedback related to the Value Proposition.

2. Update the original filled-in Value Proposition Canvas to account for the new findings. Use colors, shapes or other methods to clearly identify the new findings from the initial draft.

3. Place your name at the top of the document and submit as a PDF to Blackboard.

4. Complete the reflection prompts (provided in Appendix B).

\section{Module 4: Business Model Canvas}

\section{Part 1}

Introduction: The Business Model Canvas is a visual strategic management and lean startup template for developing new or documenting existing business models. It is a visual chart with elements describing a firm's or product's value proposition, infrastructure, customers, and finances. It assists firms in aligning their activities by illustrating potential trade-offs.

Directions:

1. Take notes during the lecture on the Value Proposition Canvas and review the presentation slides available through the learning management system.

2. Fill in the Business Model Canvas based on your findings from the value proposition assignment.

3. Place your name at the top of the document and submit as a PDF to Blackboard.

\section{Part 2}

Introduction: Good customer interviews are a cheap and fast way to kick off the search and design of your Business Model. Here are a few hints for conducting interviews: Adopt a beginner's mindset, Listen more than you talk, Ask "why" to get real motivations, Remember: the goal is to learn not sell, Always open doors at the end (provide a way for them to follow up as needed).

Directions:

1. Identify your archetype. Interview 5 people that fit the archetype. Ask questions to obtain qualitative feedback related to the Business Model.

2. Update the original filled-in Business Model Canvas to account for the new findings. Use colors, shapes or other methods to clearly identify the new findings from the initial draft.

3. Place your name at the top of the document and submit as a PDF to Blackboard.

4. Complete the reflection prompts (provided in Appendix B).

\section{APPENDIX B: Example Reflection Prompts}

1. Executive Summary (1 page minimum): Provide a summary of the competency, including the definition (with citation) and a half-page Google image (with citation). Citations should be inserted at the end as a reference (not included in the page length). Provide a paragraph explaining the benefits of the competency within the workplace, supported by 3 citations.

2. Assignment(s) Demonstrating Competency

2.1 Assignment Summary (1 page minimum): Provide a summary of the assignment explaining the artifact requirements and how the assignment was assessed. Insert an infographic PowerPoint slide summarizing the artifact. 
2.2 Assignment Pre-Assessment (1/2 page minimum): Prior to starting the assignment, identify your strengths and weaknesses with respect to your perceived ability to complete the assignment. Provide evidence and justification to support the initially identified strengths and weaknesses. Based on the assignment directions, identify at least 5 concepts, skills, or prior knowledge required to effectively complete the assignment. Rate your abilities (e.g., strengths and weaknesses) with respect to each concept, skills, or prior knowledge. Provide justification for your ratings and explain how this rating has changed over time.

2.3 Assignment Mid-Assessment (1/2 page minimum): While completing the assignment, state observations you noticed that support or hinder your initial assessment of your strengths and weaknesses with respect to completing the assignment. Describe observations you recognized while completing the assignment that support or hinder your initial assessment rating (e.g., strengths and weaknesses) of your skills, abilities, and prior knowledge.

2.4 Assignment Post-Assessment (1 page minimum): After completing the assignment, identify what you learned and insights you gained. (1) Self-Assessment: Explain whether or not your initial ratings changed. Explain whether or not you obtained deeper skill development in areas you did not initially identify (i.e. areas other than the 5 you listed in the pre-assessment) when you began the assignment. (2) Context: What was the context or topic area for the assignment? Did your knowledge increase? (3) Learning Objective: What was the main learning objective(s) of the assignment? Explain the extent to which you believe you met the learning objective of the assignment. (4) Peer Insights: How was your peer's approach to the assignment different from your approach? Based on the findings, how might you approach an assignment like this in the future? (5) Time and Effort: When did you start working on the assignment? How much time did you dedicate to the assignment? Do you think this is adequate? Why or why not? In the future, how might you approach an assignment like this again?

3. Summary of Why this Matters (1/2 page minimum): Identify what type of job or career you might like to have in the future. Why is this competency important for this type of job? Why are assignments like these important in preparing you for entering the workforce? Why are the concepts, skills, and prior knowledge required for assignments like these important to future employers?

4. Lifelong Learning (1/2 page minimum): In the future, how might you extend your knowledge related to this competency area? Be specific in identifying a minimum of 5 diverse resources (e.g., people, books, movies, government agencies, MOOCs, magazines, websites, educational institutions, courses, museums, conferences, etc...) 